\title{
Cognitive impairment as barrier to engagement in vocational services among veterans with severe mental illness
}

\author{
Maureen K. O’Connor, PsyD, ABCN $;^{1-2^{*}}$ Lisa Mueller, PhD; ${ }^{1}$ Alice Van Ormer, PhD; ${ }^{1}$ Robert Drake, PhD; ${ }^{3}$ \\ Walter Penk, PhD; ${ }^{1}$ Robert Rosenheck, MD; ${ }^{4}$ Alicia Semiatin, MA; ${ }^{1}$ Charles E. Drebing, PhD $^{1}$ \\ ${ }^{1}$ Bedford Department of Veterans Affairs (VA) Medical Center, Bedford, MA; ${ }^{2}$ Boston University School of Medicine, \\ Boston, MA; ${ }^{3}$ Dartmouth Medical School, Hanover, $\mathrm{NH} ;{ }^{4}$ VA Connecticut Healthcare System, West Haven, CT; and \\ Yale School of Medicine, New Haven, CT
}

\begin{abstract}
Vocational services (VS), particularly supported employment models, have clear advantages for assisting adults with severe mental illness (SMI) in returning to the workplace, but a majority of eligible individuals with SMI do not receive any type of VS. The reasons for nonparticipation in VS remain poorly understood, and the potential contribution of cognitive impairment as a barrier to entry has not been explored. The present study uses a pathways-to-care design to examine the specific contribution of cognitive functioning to entry into VS among veterans with SMI. We examined 179 veterans with both SMI and un- or underemployment who completed a work history, the Pathways To Care Inventory, and the Trail-Making Test, Part B. Analysis revealed that veterans with SMI and moderate to severe cognitive impairment took significantly longer to progress through pathways-to-care than those with SMI and mild or no cognitive impairment. These results suggest that identifying veterans with SMI and cognitive impairment early and providing them with integrated and adjunct services may help them navigate VS.
\end{abstract}

Clinical Trial Registration: ClinicalTrials.gov; NCT00223834, "Pathways to Vocational Rehabilitation: Enhancing Entry and Retention"; http://www.clinicaltrials.gov.

Key words: cognitive functioning, cognitive impairment, integrated services, pathways-to-care, return to work, severe mental illness, supported employment, treatment entry, vocational disability, vocational services.

\section{INTRODUCTION}

Federal and state governments have invested heavily in vocational services (VS) to help adults with disability return to work. A number of VS models have been developed and evaluated. For example, supported employment (SE), one of the most well researched models, is an evidence-based practice that demonstrates clear advantages over other forms of VS for adults with severe mental illness (SMI) [1-2]. Bond et al. summarized the results of 11 randomized clinical trials of SE programs [2]. During a 6 to 24 month period, 7 to 40 percent (mean $=23 \%$ ) of participants achieved employment in traditional programs compared with 27 to 78 percent $($ mean $=61 \%$ ) of participants in SE. SE leads not only to higher rates of competitive employment overall but also to more hours worked

Abbreviations: ANOVA $=$ analysis of variance; $\mathrm{CI}=$ confidence interval; $\mathrm{MD}=$ mean difference; $\mathrm{SE}=$ supported employment; SMI = severe mental illness; TMT-B = TrailMaking Test, Part B; VA = Department of Veterans Affairs; VAMC = VA medical center; VHA = Veterans Health Administration; $\mathrm{VS}=$ vocational services.

*Address all correspondence to Maureen K. O'Connor, PsyD, ABCN; Psychology Department, Bedford VAMC, 200 Springs Rd, Bedford, MA 01730; 781-687-2830; fax: 781-687-3224. Email: maureen.oconnor@va.gov

DOI:10.1682/JRRD.2010.06.0117 
and greater earned income [3]. While SE models have been successful, one key concern is the low national utilization rate of SE services [4]. In addition, researchers note that a subset of individuals using such services remain unemployed, have brief job tenure, or receive unsatisfactory job terminations [5-10].

In an effort to improve VS outcomes, recent models have been developed that incorporate cognitive retraining with traditional VS [11-13]. This reflects the growing evidence that the majority of individuals with SMI experience cognitive impairment early in the disease course [14], which often does not fully remit despite successful treatment of primary psychiatric symptoms [15-18], and that cognitive impairment is strongly related to vocational outcomes in this population [19-24]. McGurk and Mueser cite several reasons to suspect that the relationship between cognitive impairment and occupational functioning is causative, including empirical findings that cognitive impairment precedes limitations in role functioning, is prospectively related to work outcomes in the general population, is stable over time independent of work status, does not improve with return to work, and is subjectively noted as a barrier to employment success [22]. Combined models including cognitive services and VS appear to improve vocational outcomes when compared with traditional models, resulting in significantly greater work productivity, more hours worked, and greater wages earned [25-26].

Unfortunately, despite the promise of these newer integrated models, a majority of eligible individuals do not enter any type of VS [27-29]. The reasons for nonparticipation in VS remain poorly understood. Studies of the "pathways-to-care" examine the sequence of contacts that persons with clinical needs and their significant others can use to access care for clinical problems in an effort to document barriers to treatment entry [30]. Goldberg and Huxley proposed a pathways-to-care model that focuses on "filters" or decision points in the steps patients take to enter clinical treatment [31]. Pathwaysto-care analyses have resulted in a critical broadening of our understanding of help-seeking among individuals with SMI [32-33]. The length of delay before treatment initiation varies widely and has been linked to a range of variables, including characteristics of the clinical need, the patient, the patient's family and social setting, access to care, and characteristics of providers and healthcare systems.
Although it is well known that individuals with SMI experience cognitive impairment that interferes with successful employment, it is less clear whether cognitive impairment represents a barrier to taking the necessary steps to entering VS programs. Given the prevalence of cognitive symptoms in individuals with SMI and the important relationship between cognitive impairment and employment, we examined the potential contribution of cognitive impairment to the steps along the path to VS. In the present study, we used a prospective pathways-to-care design to determine whether impaired cognitive functioning is a barrier to entry into VS in a sample of veterans with both SMI and vocational needs. We examined the specific contribution of cognitive impairment to the time it takes veterans to progress through the following VS stages: (1) recognition of a vocational problem, (2) initiation of help-seeking behavior, and (3) participation in treatment. We hypothesized that cognitive impairment would be associated with greater delays in transitioning from one stage to the next.

\section{METHODS}

\section{Participants}

We recruited a total of 192 veterans, of which 179 were included in the study, from two program sites as part of a larger multisite study of entry and retention in VS: the Bedford Department of Veterans Affairs (VA) Medical Center (VAMC), Bedford, Massachusetts, and the Dallas VAMC, Dallas, Texas, both with extensive mental health services and VS. The Bedford VAMC is primarily a mental health and long-term care facility and has one of the largest Veterans Health Administration (VHA) VS programs in the country, with 300 unique veterans admitted per year and 200 veterans participating on an average day [34-35]. The Dallas VAMC is a tertiary care hospital that also has a full range of mental health services, as well as another of the largest VHA VS programs in the country, with about 300 unique veterans admitted per year and 250 veterans participating on an average day [34-36]. We reimbursed participants for their time spent in providing research data.

We recruited participants if they (1) met criteria for SMI as defined by the VHA Northeast Program Evaluation Center, which entails meeting diagnostic criteria for either schizophrenia or other psychotic disorder, bipolar disorder, affective disorder, or posttraumatic stress disorder 
for at least 2 years; (2) met criteria for "having vocational needs," defined as being un- or underemployed for a minimum of 3 months (being employed $\leq 20$ hours per week in day labor, temporary work, or work that requires substantially lower skill levels than prior work); (3) <60 years old; (4) were an English speaker with $>9$ years of formal education; (5) completed all measures relevant to the current study; and (6) had a Mini-Mental State Examination score of $>23$ out of 30 .

\section{Procedures}

We placed flyers around the Bedford and Dallas VAMCs and in clinic locations. Veterans who were interested in the study contacted research staff and met for a screening appointment to discuss an overview of the study and enrollment procedures, including inclusion and exclusion criteria. All veterans understood that participating in the study was completely voluntary and would have no effect on their current or future VA benefits or treatment. We then scheduled veterans who completed the informed consent process for the baseline interview.

We included the following variables and measures administered at baseline in the current analyses.

\section{Work History}

We collected specific dates of employment, average hours worked per week, and beginning and ending pay for all jobs in the prior 5 years at baseline and documented all subsequent employment at all follow-ups.

\section{Diagnosis}

We determined current diagnoses at baseline using the Structured Clinical Interview for the Diagnostic and Statistical Manual of Mental Disorders-Fourth Edition [37].

\section{Steps Taken in Pathways-to-Care}

We documented dates and steps taken with respect to initial recognition of a vocational problem, initiation of help-seeking behavior, and participation in treatment using the Pathways to Care Inventory, a structured interview developed and validated in prior work by its authors [38], which we administered at baseline and at each follow-up. This instrument collects self-report information (dates, action, and supports and barriers) regarding common steps in the pathways-to-care for vocational need, including (1) onset and course of clinical need, (2) recognition of need by the respondent and/or their family, (3) steps taken to obtain professional help, and (4) partici- pation in treatment for vocational need. The Pathways to Care Inventory is one of the few procedures for collecting pathways-to-care data for which published evidence supports its validity and reliability [38].

\section{Cognitive Functioning}

We used the Mini-Mental State Examination to document gross cognitive functioning at baseline, using the traditional cutoff for impairment of $>23$ out of 30 to screen out candidates who would likely have difficulty understanding or retaining the information discussed in the intervention [39]. We used the Trail-Making Test, Part B (TMT-B) as a more sensitive measure of cognitive functioning for all participants [40-42]. We converted TMT-B scores to $z$-scores using age-based normative data [43] and conducted all analyses using the $z$-scores. Positive $z$-scores indicated poorer performance relative to the mean performance of the age-matched normative group. The TMT-B is one of the most frequently used instruments to assess cognitive functioning [44]. Successful performance on the TMT-B requires multiple cognitive processes, including aspects of executive control such as cognitive flexibility and set maintenance [45-46], visual search and sequencing [46], motor speed and dexterity [47-48], and psychomotor processing speed [49]. As such, the TMT-B acts as a brief but predictive measure of generalized cognitive impairment [42].

\section{RESULTS}

We included 179 veterans in the current analyses. We divided the veterans into three groups based on their z-score on the TMT-B: $(1) \leq 1.39$, indicating cognitive performance within nonimpaired limits; (2) 1.4 to 1.99, indicating cognitive performance in the mildly impaired range; and (3) $\geq 2.0$, indicating cognitive performance in the moderately to severely impaired range. These cutoff scores and corresponding labels are in line with the standard established cutoff scores and labels used for interpreting performance on cognitive measures for individuals low-average and above (referred to as "no impairment group"), borderline impaired (referred to as "mild impairment group"), and impaired (referred to as "moderate to severe impairment group”) [50].

Table 1 shows sociodemographic characteristics of the full sample of 179 veterans. The sample appears fairly typical of the population served by VHA mental 
JRRD, Volume 48, Number 5, 2011

Table 1.

Sociodemographic and background characteristics of veteran sample $(n=179)$.

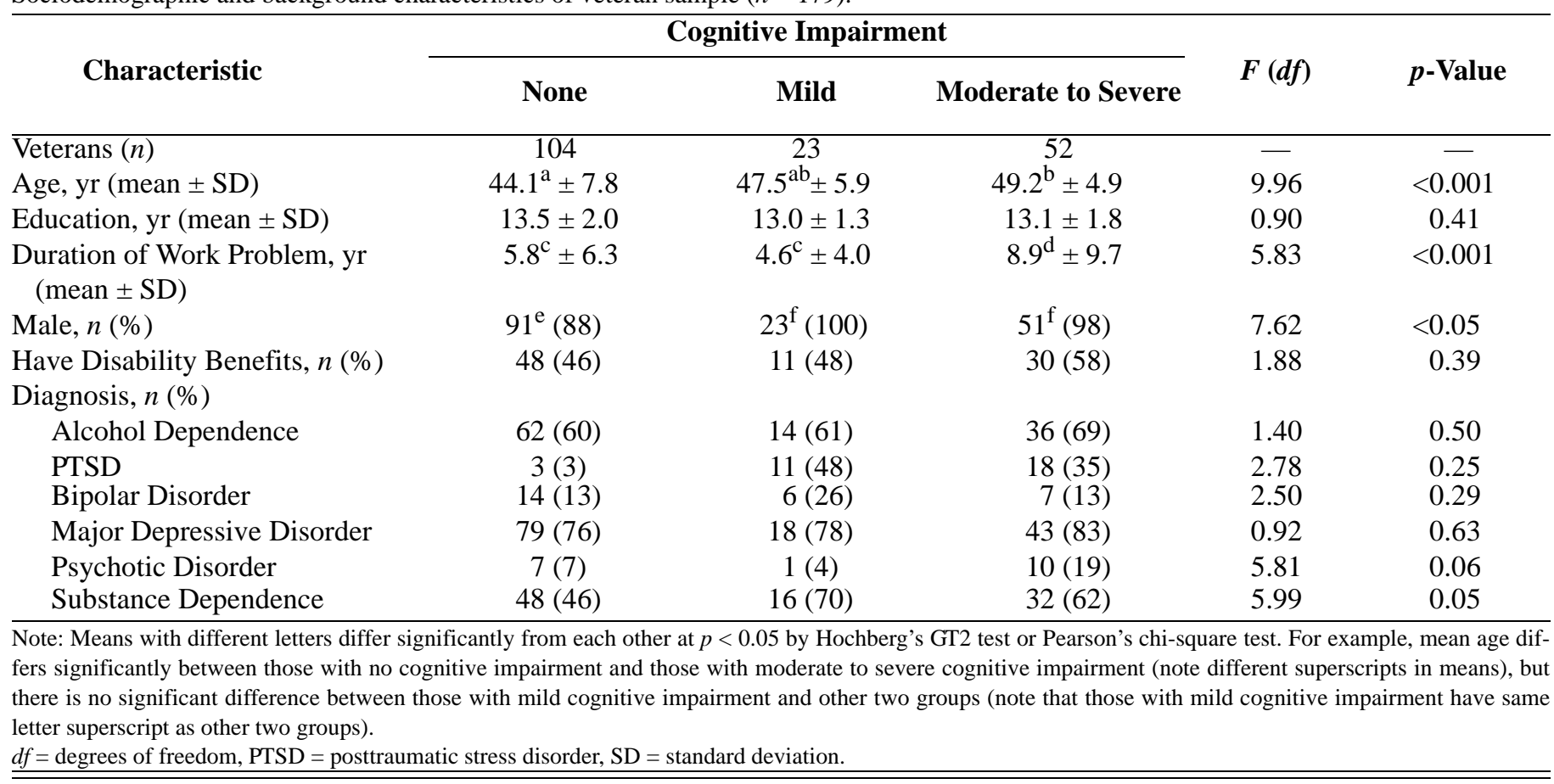

health services. Not all 179 veterans included in the analysis had data for all three pathways-to-care variables of interest, resulting in a total of 165 veterans with recognition of a vocational problem, 145 veterans who had initiated help-seeking behavior, and 133 veterans who had participated in treatment.

To examine the effect of cognitive impairment on time to progress through each of the three stages of pathways-to-care, we conducted three separate analyses of variance (ANOVAs) for each of the three stages (recognition of a vocational problem, initiation of help-seeking behavior, and participation in treatment). A significant finding would indicate that the degree of cognitive impairment as measured by the TMT-B was related to the length of time it took veterans to progress through the stages of pathways-to-care. The ANOVAs each revealed significant differences for all three stages, including time until the problem was first recognized $\left(F_{2,163}=5.56, p<\right.$ $0.01)$, time until help-seeking steps were first taken $\left(F_{2,143}=5.64, p<0.01\right)$, and time until first treatment was entered $\left(F_{2,131}=5.58, p<0.01\right)$.

Table 2 presents the average time it took veterans to progress through the pathways-to-care stages for all three groups. The moderate to severe impairment group took significantly longer to recognize that they had a problem than the no impairment and mild impairment groups, with an average of 4.44 years for the moderate to severe impairment group compared with 0.93 to 1.81 years for the no impairment or mild impairment groups, respectively. Similarly, the moderate to severe impairment group took significantly longer to seek help and enter treatment than the no impairment and mild impairment groups (6.36 vs $1.38-3.52$ yr and 6.36 vs $1.53-3.93$ yr, respectively).

To fully understand the performance differences between groups, we conducted post hoc tests using a Hochberg's GT2 correction given unequal sample sizes [51]. There was no statistical difference between the no impairment group and mild impairment group on time until problem recognition (mean difference $[\mathrm{MD}]=0.89$, $95 \%$ confidence interval $[\mathrm{CI}]=-1.96$ to $3.73, p=0.84$ ), time until initiation of help-seeking behavior (MD = $2.14,95 \% \mathrm{CI}=-1.36$ to $5.64, p=0.37$ ), or time until participation in treatment $(\mathrm{MD}=2.40,95 \% \mathrm{CI}=-0.95$ to $5.75, p=0.24)$. These results suggest that the no impairment group did not differ significantly from the mild cognitive impairment group on the time it took them to progress through the pathways-to-care (problem recognition, initiation of help-seeking behavior, participation in treatment). The moderate to severe impairment group did 
Table 2.

Comparison of general cognitive impairment groups of veterans on completion time to pathways-to-care stages (years).

\begin{tabular}{|c|c|c|c|c|c|c|}
\hline \multirow[b]{2}{*}{ Pathways-to-Care } & \multirow[b]{2}{*}{$n$} & \multicolumn{3}{|c|}{ Cognitive Impairment (mean \pm SD) } & \multirow[b]{2}{*}{$F(d f)$} & \multirow[b]{2}{*}{$p$-Value } \\
\hline & & None & Mild & $\begin{array}{l}\text { Moderate to } \\
\text { Severe }\end{array}$ & & \\
\hline $\begin{array}{l}\text { Recognition of Vocational } \\
\text { Problem }\end{array}$ & 97 & $1.81^{\mathrm{a}} \pm 3.70$ & $0.93^{\mathrm{a}} \pm 1.82$ & $4.44^{\mathrm{b}} \pm 7.62$ & $5.56(2,163)$ & 0.005 \\
\hline $\begin{array}{l}\text { Initiation of Help-Seeking } \\
\text { Behavior }\end{array}$ & 22 & $3.52^{\mathrm{C}} \pm 5.54$ & $1.38^{\mathrm{C}} \pm 2.13$ & $6.36^{\mathrm{d}} \pm 8.15$ & $5.64(2,143)$ & 0.004 \\
\hline Participation in Treatment & 47 & $3.93^{\mathrm{ef}} \pm 5.19$ & $1.53^{\mathrm{e}} \pm 2.12$ & $6.43^{f} \pm 7.75$ & $5.58(2,131)$ & 0.005 \\
\hline
\end{tabular}

Note: Means with different letters differ significantly from each other at $p<0.05$ by Hochberg's GT2 test. For example, participation in treatment differs significantly between those with mild cognitive impairment and those with moderate to severe cognitive impairment (note different superscripts in means), but there is no significant difference between those with no cognitive impairment and other two groups (note that those with no cognitive impairment have same letter superscript as other two groups).

$f=$ degrees of freedom, $\mathrm{SD}=$ standard deviation.

differ significantly from the no impairment and mild impairment groups on time until problem recognition $(\mathrm{MD}=-2.63,95 \% \mathrm{CI}=-4.77$ to -0.49 and $\mathrm{MD}=-3.51$, $95 \% \mathrm{CI}=-6.62$ to -0.41 , respectively, $p<0.05$ ) and time until initiation of help-seeking behavior $(\mathrm{MD}=-2.84$, $95 \% \mathrm{CI}=-5.62$ to -0.06 and $\mathrm{MD}=-4.98,95 \% \mathrm{CI}=$ -8.78 to -1.18 , respectively, $p<0.05$ ). The moderate to severe impairment group did not differ significantly from the no impairment group on time until participation in treatment $(\mathrm{MD}=-2.50,95 \% \mathrm{CI}=-5.24$ to $0.24, p=$ 0.09), but examination of the means (Table 2) revealed a trend in the expected direction. However, the moderate to severe impairment group did differ significantly from the mild impairment group on time until participation in treatment $(\mathrm{MD}=-4.90,95 \% \mathrm{CI}=-8.53$ to $-1.26, p<$ $0.05)$. Taken together, these results suggest that veterans who experience moderate to severe cognitive impairment take significantly longer to recognize they have a vocational problem, seek help for that problem, and enter treatment than veterans with no cognitive impairment or mild cognitive impairment.

\section{DISCUSSION}

This is the first study we are aware of that examines the effect of cognitive impairment on time to progress through the steps required for veterans with SMI to enter VS. Veterans with moderate to severe cognitive impairment took significantly longer to progress through the pathways-to-care relative to veterans with no cognitive impairment and mild cognitive impairment. Our results underscore the importance of evaluating cognitive func- tioning in individuals with SMI. It is well known that a majority of individuals with SMI exhibit impairments in cognition that begin early in the disease course and may not fully remit even with successful treatment of other psychiatric symptoms [15-18]. These impairments have been consistently related to poor occupational outcomes [19-22]. The current results suggest that cognitive impairment also acts as a barrier to entry into VS and raises the possibility that it is associated with delays in the use of other healthcare services as well.

The importance of increasing provider awareness regarding the effect of cognitive limitations in SMI is highlighted by the findings presented here. Efforts to include cognitive impairment in the diagnostic criteria of SMI have emphasized benefits such as increasing provider awareness about the important role of cognition in the management and treatment of individuals with SMI [23,52-54]. Successful employment has been associated with significant benefits for those with SMI, including improvements in psychiatric symptoms, lower rates of psychiatric hospitalizations, and reduced social stigma [2,4,55-58]. Those with both SMI and cognitive impairment are less likely to reap these rewards because of greater delays in entry to VS but may derive great benefit from additional supports to obtain needed VS. Given the many positive benefits of return to work for individuals with SMI, increased provider awareness about the effect of cognitive impairment on VS and early identification of individuals with both SMI and cognitive impairment may be the first step in improving progression through the pathways-to-care to VS.

Those with both SMI and moderate to severe cognitive impairment appear most vulnerable to delayed seeking 
of VS in part because of a longer latency in recognizing that a vocational problem exists. Those with SMI often display discrepancies in their perception of VS needs relative to care providers and family members [57-60]. One study found only modest correlations between individuals with SMI and case manager ratings on perceived need for VS [61]. A recent study examining self-reported need for employment among an outpatient sample of 195 individuals with mental illness found that consumers' self-reported need for employment was more strongly related to their decisions to accept SE referrals than their practitioners' referral decisions, suggesting that it is the personal recognition of an employment problem that is most relevant to the decision to accept VS referrals [27]. While many other factors, such as loss of confidence, fears of returning to work, and negative expectations, can contribute to perceptions of need for VS, the current findings both suggest a link between cognitive impairment and impaired levels of awareness and support neuropsychological models of self awareness, which conceptualize lack of awareness as arising from disruption of neuroanatomical systems.

These results highlight the importance of identifying individuals with both SMI and cognitive impairment early so that efforts can be made to increase awareness of vocational disability and promote faster progression to help-seeking behavior. One way to accomplish this would be to mandate that providers screen individuals with SMI for vocational need at the time of intake or initial presentation for mental health services. The results of the current study suggest that even a brief test of cognitive functioning can have practical predictive value for those with SMI and vocational need and imply that incorporating brief cognitive measures into screening may offer a useful starting point for providers working with this population. Feedback regarding the results of the screen can then be provided to the client and others involved in their care to increase awareness of the vocational problem and the potential role that cognitive impairment may play in vocational rehabilitation.

Although efforts to increase awareness of a vocational problem can begin to address barriers to rehabilitation, even after recognizing the vocational problem, veterans with moderate to severe cognitive impairment still took significantly longer to seek help and to enter treatment relative to their peers with no cognitive impairment. This suggests that improving recognition of a vocational problem alone is not enough. Cognitive impairment has been linked to deficiencies in self-initiated, proactive problem solving in a sample of adults diagnosed with schizophrenia [62]. Individuals with psychiatric disorders tend to use more passive coping styles compared with nondisabled controls [63-64], perhaps because of cognitive impairment. Direct assistance and guidance through the steps of initiation of help-seeking behavior and participation in treatment may then be most important for individuals with SMI and cognitive impairment. One way to improve these pathways-to-care stages following recognition of a vocational problem would be full integration of VS and mental health services. Traditionally, mental health services and VS were provided by separate organizations and/or programs. Although this may have some advantages, the limitation is that the individual with SMI may have to initiate and follow through with VS goals without the direct assistance and guidance of clinicians intimately involved in caring for their mental health issues. Integrated programs offer the advantage of motivating clients toward vocational pursuits and individually tailoring the level of support and follow-up needed for a clinical outcome that includes employment. There have been several successful efforts to integrate mental health services and VS [65-66], and studies have provided support for the effectiveness of integrated models over the traditional brokered service model, which uses separate agencies for mental health and VS [67-71].

There are several limitations to the current study. One is that we only used one measure of cognitive functioning: TMT-B. While the TMT-B is considered a sensitive measure of cognitive dysfunction, using several measures of cognitive functioning may have resulted in different findings. For example, interestingly, veterans in our study with mild cognitive impairment did not significantly differ from those with no cognitive impairment on time to progress through the pathways-to-care and seemed to fare better when we examined the mean time to progress through each stage. One possible explanation for this somewhat paradoxical finding is the idea that veterans with mild impairment are more readily identified as needing help than those with no impairment, who may go unnoticed and yet may still need some external support to progress through the pathways-to-care. It is also possible, of course, that this finding has to do with methodological issues such as the sensitivity of the TMT-B or the way we constructed the three groups. It is also important to note that other factors that might covary with TMT-B performance (e.g., psychiatric symptoms, medication effects) and 
affect interpretation of the results are unexplored in this study. Another limitation concerns the primary method of gathering data through patient interview. This method of reliance on self-report inherently raises questions about the accuracy of the data gathered. In the current study, we used several methods to help ensure collection of the most accurate data, but it is possible that objective measures would reveal different results. Another consideration is the idea that other factors that can influence progress through the pathways-to-care might have played a role in the time to complete each step. Not all such factors are taken into account with the pathways-to-care model, raising an inherent possible limitation in using this model. For example, family members, friends, clinicians, and benefits programs can influence a veteran's progress through the pathways-to-care. In order to attempt to address this weakness, we collected self-report information about whether other people or programs served as supports or barriers, finding that approximately 50 percent of the participants reported at least one clinician and family member as supportive of employment and more than a third cited a friend as supportive. At the same time, 40 percent of the participants reported that a clinician had discouraged work, and a third reported that a family member had discouraged work. Of the participants, 50 percent were receiving benefits at the time of the interview and 37 percent of the sample reported a concern about losing their benefits. The extent to which these supports or barriers affected overall progress through the pathways-tocare is unknown and bears future exploration. In addition, in this study, we defined a vocational problem as being un- or underemployed. Although 96 percent of the participants at the time of interview reported recognizing themselves as having a vocational problem, it is possible that some participants made a decision to remain un- or underemployed because of factors such as income limits imposed by benefits programs.

\section{CONCLUSIONS}

Overall, these results have several implications for improving efforts to return individuals with SMI to the workplace. Routine cognitive screening or neuropsychological evaluation can help identify the subset of individuals with both SMI and cognitive impairment who might be most at risk for delayed entry into VS. Identification of these individuals can guide subsequent efforts to intervene early to ensure timely entry into VS. Suggestions for improving entry into VS for this group include incorporation of vocational screening instruments and provision of feedback regarding vocational issues to increase awareness of vocational problems. Integration of mental health services and VS can help provide direct guidance to vocational resources for individuals with both SMI and cognitive impairment that may have increased the need for external support, motivation, and assistance with coping and problem solving as resources are navigated. Future research should focus on the effect of routine screening for vocational issues in mental health settings, the usefulness of increasing provider awareness of the role of VS in recovery, and the potential differential effect of integrated vocational programs for those with and without cognitive impairment. An examination of specific cognitive domains related to entry into vocational rehabilitation would also help extend the findings presented here.

\section{ACKNOWLEDGMENTS}

\section{Author Contributions:}

Study concept and design: M. K. O’Connor.

Acquisition of data and statistical analysis: L. Mueller, M. K. O’Connor. Analysis and interpretation of data: C. E. Drebing, M. K. O’Connor.

Drafting of manuscript: M. K. O’Connor, A. Semiatin.

Critical revision of manuscript for important intellectual content:

L. Mueller, C. E. Drebing, R. Drake, R. Rosenheck, A. Van Ormer,

W. Penk, A. Semiatin.

Study supervision: C. E. Drebing, M. K. O’Connor.

Financial Disclosures: The authors have declared that no competing interests exist.

Funding/Support: This material was based on work supported by the VHA Office of Rehabilitation Research and Development (grant F3436R).

Additional Contributions: We gratefully acknowledge Patricia Duffy, PsyD, for assisting with data collection and entry. As always, we are indebted to the veterans and families that participated in this project.

Institutional Review: The study was approved by the site-specific institutional review boards (Bedford VAMC and Dallas VAMC). All VA requirements for research involving human participants were met. Veterans who were interested and eligible to enroll completed the informed consent process.

Participant Follow-Up: The authors do not intend to inform participants of the publication of this study. 


\section{REFERENCES}

1. Mueser KT, Salyers MP, Mueser PR. A prospective analysis of work in schizophrenia. Schizophr Bull. 2001;27(2): 281-96. [PMID: 11354595]

2. Bond GR, Resnick SG, Drake RE, Xie H, McHugo GJ, Bebout RR. Does competitive employment improve nonvocational outcomes for people with severe mental illness? J Consult Clin Psychol. 2001;69(3):489-501.

[PMID: 11495178]

DOI:10.1037/0022-006X.69.3.489

3. Jablensky A, McGrath J, Herrman H, Castle D, Guereje O, Morgan V, Korten A. People living with psychotic illness: An Australian study 1997-1998. Canberra (Australia): Commonwealth Department of Health and Aged Care; 1999.

4. Marwaha S, Johnson S. Schizophrenia and employment-A review. Soc Psychiatry Psychiatr Epidemiol. 2004;39(5): 337-49. [PMID: 15133589] DOI:10.1007/s00127-004-0762-4

5. Cook JA. Job ending among youth and adults with severe mental illness. J Mental Health Adm. 1992;19(2):158-69. [PMID: 10121508]

DOI:10.1007/BF02521316

6. MacDonald-Wilson KL, Revell WG, Nguyen N, Peterson ME. Supported employment outcomes for people with psychiatric disability: A comparative analysis. J Vocat Rehabil. 1991;1(3):30-44.

7. Fabian E, Wiedefeld MF. Supported employment for severely psychiatrically disabled persons: A descriptive study. Psychosocial Rehabil J. 1989;2(13):53-60.

8. Gervey R, Bedell JR. Supported employment in VS. In: Bedell JR, editor. Psychological assessment and treatment of persons with severe mental disorders. Washington (DC): Taylor \& Francis; 1994. p. 139-63.

9. Black BJ. Work and mental illness: Transitions to employment. Baltimore (MD): Johns Hopkins University Press; 1988.

10. Bond GR, McDonel EC. Vocational rehabilitation outcomes for persons with psychiatric disabilities: An update. J Vocat Rehabil. 1991;1(3):9-20.

11. McGurk SR, Mueser K, DeRosa TJ, Wolfe R. Work, recovery, and comorbidity in schizophrenia: A randomized controlled trial of cognitive remediation. Schizophr Bull. 2009;35(2):319-35. [PMID: 19269925]

DOI:10.1093/schbul/sbn182

12. Bell M, Fiszdon J, Greig T, Wexler B, Bryson G. Neurocognitive enhancement therapy with work therapy in schizophrenia: 6-month follow-up of neuropsychological performance. J Rehabil Res Dev. 2007;44(5):761-70.

[PMID: 17943687]

DOI:10.1682/JRRD.2007.02.0032

13. Lindenmayer JP, McGurk SR, Mueser KT, Khan A, Wance D, Hoffman L, Wolfe R, Xie H. A randomized controlled trial of cognitive remediation among inpatients with persistent mental illness. Psychiatr Serv. 2008;59(3):241-47.

[PMID: 18308903]

DOI:10.1176/appi.ps.59.3.241

14. Galderisi S, Davidson M, Kahn RS, Mucci A, Boter H, Gheorghe MD, Rybakowski JK, Dolfus S, López-Ibor JJ, Peuskens J, Hranov LG, Fleischhacker WW; EUFEST Group. Correlates of cognitive impairment in first episode schizophrenia: The EUFEST Study. Schizophr Res. 2009; 115(2-3):104-14. [PMID: 19822407]

DOI:10.1016/j.schres.2009.09.022

15. Martinez-Aran A, Vieta E, Colom F, Reinares M, Benabarre A, Torrent C, Goikolea JM, Corbella B, SánchezMoreno J, Salamero M. Neuropsychological performance in depressed and euthymic bipolar patients. Neuropsychobiology. 2002;46 Suppl 1:16-21. [PMID: 12571428] DOI:10.1159/000068016

16. Van Gorp WG, Altshuler L, Theberge DC, Wilkins J, Dixon W. Cognitive impairment in euthymic bipolar patients with and without prior alcohol dependence. Arch Gen Psychiatry. 1998;55(1):41-46. [PMID: 9435759] DOI:10.1001/archpsyc.55.1.41

17. Quraishi S, Frangou S. Neuropsychology of bipolar disorder: A review. J Affect Disord. 2002;72(3):209-26.

[PMID: 12450638] DOI:10.1016/S0165-0327(02)00091-5

18. Osuji I, Cullum C. Cognition in bipolar disorder. Psychiatr Clin North Am. 2005;28(2):427-41. [PMID: 15826741] DOI:10.1016/j.psc.2005.02.005

19. Bryson G, Bell M, Kaplan E, Greig T. The functional consequences of memory impairments on initial work performance in people with schizophrenia. J Nerv Ment Dis. 1998;186(10):610-15. [PMID: 9788637] DOI:10.1097/00005053-199810000-00004

20. McGurk SR, Meltzer HY. The role of cognition in vocational functioning in schizophrenia. Schizophr Res. 2000; 45(3):175-84. [PMID: 11042435] DOI:10.1016/S0920-9964(99)00198-X

21. Tsang H, Ng B, Chiu I, Mann S. Predictors of post-hospital employment status for psychiatric patients in Hong Kong: From perceptions of rehabilitation professionals to empirical evidence. Int J Soc Psychiatry. 2000;46(4):306-12. [PMID: 11201351] DOI:10.1177/002076400004600407

22. McGurk SR, Mueser KT. Cognitive functioning, symptoms, and work in supported employment: A review and heuristic model. Schizophr Res. 2004;70(2-3):147-73. [PMID: 153293] DOI:10.1016/j.schres.2004.01.009

23. Keefe RS, Fenton WS. How should DSM-V criteria for schizophrenia include cognitive impairment? Schizophr Bull. 
2007;33(4):912-20. [PMID: 17567627]

DOI:10.1093/schbul/sbm046

24. McGurk S, Mueser K, Pascaris A. Cognitive training and supported employment for persons with severe mental illness: One-year results from a randomized controlled trial. Schizophr Bull. 2005;31(4):898-909. [PMID: 16079391] DOI:10.1093/schbul/sbi037

25. McGurk SR, Wykes T. Cognitive remediation and vocational rehabilitation. Psychiatr Rehabil J. 2008;31(4):350-59. [PMID: 18407885] DOI:10.2975/31.4.2008.350.359

26. Bell M, Bryson G, Wexler BE. Cognitive remediation of working memory deficits: Durability of training effects in severely impaired and less severely impaired schizophrenia. Acta Psychiatr Scand. 2003;108(2):101-9. [PMID: 12823166] DOI:10.1034/j.1600-0447.2003.00090.x

27. Wexler BE, Bell MD. Cognitive remediation and vocational rehabilitation for schizophrenia. Schizophr Bull. 2005; 31(4):931-41. [PMID: 16079390$]$

DOI:10.1093/schbul/sbi038

28. Casper ES, Carloni C. Increasing the utilization of supported employment services with the need for change scale. Psychiatr Serv. 2006;57(10):1430-34. [PMID: 17035560] DOI:10.1176/appi.ps.57.10.1430

29. Crowther R, Marshall M. Employment rehabilitation schemes for people with mental health problems in the North West region: Service characteristics and utilisation. J Ment Health. 2001;10(4):373-81. DOI:10.1080/09638230120041137

30. Drebing CE, Rosenheck R, Schutt R, Kasprow WJ, Penk W. Patterns in referral and admission to vocational rehabilitation associated with co-existing psychiatric and substance use disorders. Rehabil Counsel Bull. 2003;47(1):15-23. DOI:10.1177/00343552030470010301

31. Goldberg D, Huxley P. Mental illness in the community: Pathway to psychiatric care. London (England): Tavistock Publications; 1980.

32. Larsen TK, Johannessen JO, Opjordsmoen S. First-episode schizophrenia with long duration of untreated psychosis. Pathways to care. Br J Psychiatry Suppl. 1998;172(33):45-52. [PMID: 9764126]

33. Addington J, Van Mastrigt S, Hutchinson J, Addington D. Pathways to care: Help seeking behaviour in first episode psychosis. Acta Psychiatr Scand. 2002;106(5):358-64. [PMID: 12366470] DOI:10.1034/j.1600-0447.2002.02004.X

34. Kurtz M, Wexler B, Bell M. The Penn Conditional Exclusion Test (PCET): Relationship to the Wisconsin Card Sorting Test and work function in patients with schizophrenia. Schizophr Res. 2004;68(1):95-102. [PMID: 15037343] DOI:10.1016/S0920-9964(03)00179-8
35. Drebing CE, Penk W, Rosenheck R. Readiness for competitive employment: Predicting "success" of CWT graduates. Proceedings of the Annual Convention of the American Psychological Association; 2000 Aug 4-8; Washington, DC.

36. Resnick SG, Rosenheck RA. Scaling up the dissemination of evidence-based mental health practice to large systems and long-term time frames. Psychiatr Serv. 2009;60(5): 682-85. [PMID: 19411358]

DOI:10.1176/appi.ps.60.5.682

37. First MB, Spitzer RL, Gibbon M. User's guide for the Structured Clinical Interview for DSM-IV Axis I Disorders, Research Version (SCID-I, Version 2.0). New York (NY): Biometrics Research; 1996.

38. Drebing C, Movitz R, Lyon P, Harden T, McCarty E, Herz L. Documenting pathways to dementia care: Relative validity of questionnaire, interview, and medical record formats. Am J Alzheimers Dis Other Demen. 2004;19(3):187-97. [PMID: 15214206] DOI:10.1177/153331750401900306

39. Folstein MF, Folstein SE, McHugh PR. "Mini-mental State." A practical method for grading the cognitive state of patients for the clinician. J Psychiatr Res. 1975;12(3):189-98. [PMID: 1202204] DOI:10.1016/0022-3956(75)90026-6

40. Reitan R. Validity of the Trail Making Test as an indicator of organic brain damage. Percept Mot Skills. 1958;8:271-76. DOI:10.2466/PMS.8.7.271-276

41. Arbuthnott K, Frank J. Trail Making Test, Part B as a measure of executive control: Validation using a set-switching paradigm. J Clin Exp Neuropsychol. 2000;22(4):518-28. [PMID: 10923061] DOI:10.1076/1380-3395(200008)22:4;1-0;FT518

42. Crowe SF. The differential contribution of mental tracking, cognitive flexibility, visual search, and motor speed to performance on parts A and B of the Trail Making Test. J Clin Psychol. 1998;54(5):585-91. [PMID: 969108] DOI:10.1002/(SICI)1097-4679(199808)54:5<585::AIDJCLP4>3.0.CO;2-K

43. Drebing C, Van Gorp W, Stuck A, Beck J, Mitrushina M. Early detection of cognitive decline in high functioning older adults: Sensitivity and specificity of a neuropsychological screening battery. Neuropsychol. 1994;8:31-37. DOI:10.1037/0894-4105.8.1.31

44. Kennedy K. Age effects on Trail Making Test performance. Percept Mot Skills. 1981;52(2):671-75. [PMID: 7255077]

45. Kortte KB, Horner MD, Windham WK. The Trail Making Test, Part B: Cognitive flexibility or ability to maintain set? Appl Neuorpsychol. 2002;9(2):106-9. [PMID: 12214820] DOI:10.1207/S15324826AN0902 5

46. Ehrenstein WH, Heister G, Cohen R. Trail Making Test and visual search. Arch Psychiatr Nervenkr. 1982;231(4):333-38. 
[PMID: 7115051]

DOI:10.1007/BF00345589

47. Gaudino EA, Geisler MW, Squires NK. Construct validity of the Trail Making Test: What makes Trail B harder? J Clin Exp Neuropsychol. 1995;17(4):529-35. [PMID: 7593473] DOI:10.1080/01688639508405143

48. Woodruff GR, Mendoza JE, Dickson AL, Blanchard E, Christenberry LB. The effects of configural differences on the Trail Making Test. Arch Clin Neuropsychol. 1995; 10(4):408.

49. Schear JM, Sato SD. Effects of visual acuity and visual motor speed and dexterity on cognitive test performance. Arch Clin Neuropsychol. 1989;4(1):25-32.

[PMID: 14589551]

50. Stuss D, Levine B. Adult clinical neuropsychology: Lessons from studies of the frontal lobes. Annu Rev Psychol. 2002;53:401-33. [PMID: 1175291]

DOI:10.1146/annurev.psych.53.100901.135220

51. Post-hoc procedures. In: Field AP, editor. Discovering statistics using SPSS. 3rd ed. London (UK): Sage Publications; 2009. p. 374-75.

52. Krabbendam L, Arts B, Van Os J, Aleman A. Cognitive functioning in patients with schizophrenia and bipolar disorder: A quantitative review. Schizophr Res. 2005;80(2-3): 137-49. [PMID: 16183257]

DOI:10.1016/j.schres.2005.08.004

53. Strauss ME. Relations of symptoms to cognitive deficits in schizophrenia. Schizophr Bull. 1993;19(2):215-31.

[PMID: 8322033]

54. Keefe R. Review of "Health and mental health care policy: A biopsychosocial perspective (2nd ed.).” Best Pract Ment Health Int J. 2008;4(1):123-24.

55. Burns T, Catty J, White S, Becker T, Koletsi M, Fioritti A, Rössler W, Tomov T, Van Busschbach J, Wiersma D, Lauber C; EQOLISE Group. The impact of supported employment and working on clinical and social functioning: Results of an international study of individual placement and support. Schizophr Bull. 2005;35(5):949-58.

[PMID: 18403375]

DOI:10.1093/schbul/sbn024

56. Dunn EC, Wewiorski NJ, Rogers ES. The meaning and importance of employment to people in recovery from serious mental illness: Results of a qualitative study. Psychiatr Rehabil J. 2008;32(1):59-62. [PMID: 18614451] DOI:10.2975/32.1.2008.59.62

57. Fordyce DJ, Roueche JR. Changes in perspectives of disability among patients, staff, and relatives during rehabilitation for brain injury. Rehabil Psychol. 1986;31(4):217-29.

58. Sherer M, Hart T, Nick TG, Whyte J, Thompson R, Yablon S. Early impaired self-awareness after traumatic brain injury. Arch Phys Med Rehabil. 2003;84(2):168-76.
[PMID: 12601646]

DOI:10.1053/apmr.2003.50045

59. Ezrachi O, Ben-Yishay Y, Kay T, Diller L, Rattock J. Predicting employment in traumatic brain injury following neuropsychological rehabilitation. J Head Trauma Rehabil. 1991;6(3):71-84.

DOI:10.1097/00001199-199109000-00010

60. Malec JF, Buffington A, Moessner AM, Degiorgio L. A medical/vocational case coordination system for persons with brain injury: An evaluation of employment outcomes. Arch Phys Med Rehabil. 2000;81(8):1007-15. [PMID: 10943747] DOI:10.1053/apmr.2000.6980

61. Goverover Y. Categorization, deductive reasoning, and self-awareness: Association with everyday competence in persons with acute brain injury. J Clin Exp Neuropsychol. 2004;26(6):737-49. [PMID: 15370372] DOI:10.1080/13803390490509321

62. McGlynn SM, Schacter DL. Unawareness of deficits in neuropsychological syndromes. J Clin Exp Neuropsychol. 1989;11(2):143-205. [PMID: 2647781$]$

DOI:10.1080/01688638908400882

63. Prigatano GP. Disturbances of self-awareness of deficit after traumatic brain injury. In: Prigatano GP, Schacter DL, editors. Awareness of deficit after brain injury: Clinical and theoretical issues. New York (NY): Oxford University Press; 1991. p. 111-26.

64. Ownsworth T, McKenna K. Investigation of factors related to employment outcome following traumatic brain injury: A critical review and conceptual model. Disabil Rehabil. 2004;26(13):765-83. [PMID: 15371049] DOI:10.1080/09638280410001696700

65. Wilder-Willis K, Shear P, Steffen J, Borkin J. The relationship between cognitive dysfunction and coping abilities in schizophrenia. Schizophr Res. 2002;55(3):259-67.

[PMID: 12048149] DOI:10.1016/S0920-9964(01)00211-0

66. Van den Bosch RJ, Rombouts R. Coping and cognition in schizophrenia and depression. Compr Psychiatry. 1997;38(6): 341-44. [PMID: 9406740] DOI:10.1016/S0010-440X(97)90930-5

67. Drake RE, McHugo GJ, Becker DR, Anthony WA, Clark RE. The New Hampshire study of supported employment for people with severe mental illness. J Consult Clin Psychol. 1996;64(2):391-99. [PMID: 8871423] DOI:10.1037/0022-006X.64.2.391

68. Volgrath M, Alnaes R, Torgesen S. Coping and MCM-II symptom scales. J Clin Psychol. 1994;50(5):727-36. [PMID: 7806650]

69. Blankertz L, Robinson S. Adding a vocational focus to mental health rehabilitation. Psychiatr Serv. 1996;47(11): 1216-22. [PMID: 8916239] 
70. Bond GR. Supported employment: Evidence for an evidencebased practice. Psychiatr Rehabil J. 2004;27(4):345-59. [PMID: 15222147] DOI:10.2975/27.2004.345.359

71. Mowbray C, Rusilowski-Clover G, Arnold J, Allen C, Harris S, McCrohan N, Greenfield A. Project WINS: Integrating vocational services on mental health case management teams. Community Ment Health J. 1994;30(4):347-62. [PMID: 7956111] DOI:10.1007/BF02207488

Submitted for publication June 22, 2010. Accepted in revised form January 6, 2011.
This article and any supplementary material should be cited as follows:

O’Connor MK, Mueller L, Van Ormer A, Drake R, Penk W, Rosenheck R, Semiatin A, Drebing CE. Cognitive impairment as barrier to engagement in vocational services among veterans with severe mental illness. J Rehabil Res Dev. 2011;48(5):597-608.

DOI:10.1682/JRRD.2010.06.0117

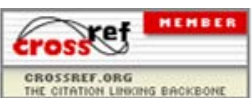


